Check for updates

Cite this: RSC Adv., 2018, 8, 21528

Received 28th April 2018

Accepted 6th June 2018

DOI: $10.1039 / \mathrm{c} 8 \mathrm{ra} 03664 \mathrm{k}$

rsc.li/rsc-advances

\section{Iron-doped $\mathrm{ZnO}$ as a support for Pt-based catalysts to improve activity and stability: enhancement of metal-support interaction by the doping effect $\uparrow$}

\author{
Si Bui Trung Tran, ${ }^{a}$ Han Seul Choi, ${ }^{\text {ab }}$ Sun Young Oh, ${ }^{\text {ab }}$ Song Yi Moon ${ }^{\text {ab }}$ \\ and Jeong Young Park (DD *ab
}

\begin{abstract}
In heterogeneous catalysis, the role of the interface between a metal and a metal oxide in deciding catalytic performance has remained a long-standing question. Out of many molecular-scale factors that affect the properties of metal-oxide interfaces, doping or impurities in the oxides can result in excess charge carriers or oxygen vacancies on the oxides, which lead to a change in catalytic activity. For a model system with a tunable dopant, we employed Pt nanoparticles with Fe doping. We synthesized a series of Fe-doped $\mathrm{ZnO}$ with different Fe loadings (i.e., 0,1 , and 4\%) using the co-precipitation method, and then deposited $\mathrm{Pt}$ nanoparticles onto these supports. The Pt-based catalysts were employed to investigate the effect of the dopant to promote the catalytic performance for the CO oxidation reaction. The $4 \% \mathrm{Fe}$ loading sample showed the highest catalytic activity among the catalysts, with a turnover frequency of $5.37 \mathrm{~s}^{-1}$ at $126{ }^{\circ} \mathrm{C}$. The dopant was found to enhance the interaction between the Pt nanoparticles and the catalyst support, including the prevention of metal sintering, which resulted in an improvement of catalytic activity.
\end{abstract}

\section{Introduction}

In heterogeneous catalysis, the interface between a metal and a metal oxide plays a crucial role in deciding catalytic performance. Schwab et al. showed an increase in catalytic activity for methanol oxidation on an $\mathrm{Ag} / \mathrm{ZnO}$ catalyst based on the existence of an interaction between $\mathrm{Ag}$ and $\mathrm{ZnO} .{ }^{1}$ Later, the classical strong metal-support interaction (SMSI) effect, discovered by Tauster et. al. on $\mathrm{TiO}_{2}$ supported on a group VIII metal, ${ }^{2}$ involved the transfer of electrons from the catalyst support to the metal after $\mathrm{H}_{2}$ treatment at high temperature. Since then, the SMSI effect has been studied and extended to other phenomena related to the interaction between a metal and a metal oxide, which determines both the catalytic activity and selectivity. ${ }^{3-8}$ The electronic factor that originates from charge transfer at the interface between the metal and the oxide support, and the geometric factor that results from a change in the metal and/or metal oxide morphological structure are used

${ }^{a}$ Centre for Nanomaterials and Chemical Reactions, Institute of Basic Science (IBS), Daejeon 305-701, Republic of Korea. E-mail: jeongypark@kaist.ac.kr

${ }^{b}$ Graduate School of EEWS and Department of Chemistry, Korea Advanced Institute of Science and Technology (KAIST), Daejeon 305-701, Republic of Korea

$\dagger$ Electronic supplementary information (ESI) available: Photograph of the samples (Fig. S1). SEM image and corresponding EDS mapping of the Pt/4\% FeZnO sample (Fig. S2). XPS spectra of Fe 2p and Zn 2p (Fig. S3). TEM images of $\mathrm{Pt} / \mathrm{ZnO}, \mathrm{Pt} / 1 \% \mathrm{FeZnO}$, and $\mathrm{Pt} / 4 \% \mathrm{FeZnO}$ samples collected after the $\mathrm{CO}$ oxidation reaction and their corresponding particle size distributions (Fig. S4). See DOI: $10.1039 / \mathrm{c} 8 \mathrm{ra} 03664 \mathrm{k}$ to rationalize the SMSI effect. ${ }^{9-12}$ With respect to geometric factors, when the interaction between the metal and metal oxide is very weak, metal nanoparticles (NPs) have a tendency to agglomerate to form larger NPs on the metal oxide surface, known as the sintering effect. However, when this interaction is strong, encapsulation of the metal by the metal oxide is often observed, thus maximizing the interfacial area. As a nanostructure of metal particles is vitally important in catalysis, the design of novel catalysts with the desired metal-support interaction is beneficial for improving catalytic performance.

Since metal oxides have been employed as catalyst supports for a variety of industrial processes, ${ }^{13-15}$ there is great demand for optimizing their properties to improve catalytic performance. Among the different methods to achieve this goal, the substitution of a minor fraction of the cations in the host oxide lattice with external metal ions, referred to as the doping process, has gained much attention. ${ }^{16-18}$ This process can modify the electronic structure as well as the physical structure (e.g., the crystallinity or surface area) of the host oxide. As a result, when doped metal oxides are used as catalyst supports, this modification inevitably leads to a change in the interaction between the doped metal oxide and the metal NPs grown on them. This strategy has been utilized for the development of novel doped catalysts that are able to control catalytic performance. ${ }^{19,20}$ For instance, Schumann et al. investigated the dopant effect of $\mathrm{Al}, \mathrm{Ga}$, and $\mathrm{Mg}$ on the support in $\mathrm{Cu} / \mathrm{ZnO}$ catalysts for methanol synthesis and the reverse water-gas shift reaction. ${ }^{21}$ They found that the dopants $\mathrm{Al}^{3+}$ and $\mathrm{Ga}^{3+}$ 
improved the electronic contribution to the reverse water-gas shift reaction and promoted structural contributions in methanol synthesis, while $\mathrm{Mg}^{2+}$ had no beneficial influence on the activity. Peng et al. introduced $\mathrm{Mg}^{2+}$ into $\mathrm{ZnO}$ to improve the catalytic stability for CO oxidation coupling to dimethyl oxalate. ${ }^{22}$ A small portion of the $\mathrm{Mg}^{2+}$ was found to be incorporated into the lattice of the $\mathrm{ZnO}$ support, which led to a SMSI caused by electron transfer from the $\mathrm{ZnO}$ to the Pd NPs. Apparently, a small amount of dopant can contribute to a change in the catalytic outcome; hence, understanding the influence of dopants on catalytic performance would be interesting and desirable to research further.

The semiconductor $\mathrm{ZnO}$ has been considered as a host oxide for doping different metal ions to alter their physical and chemical properties. ${ }^{23,24} \mathrm{ZnO}$, which belongs to the group of non-reducible metal oxides because of their intrinsic resistance to any change in oxidation state, is highly stoichiometric, stable, and chemically inert. Therefore, when it is doped with other metal ions, any change in catalytic performance should be attributed to the dopant. Herein, we employed Fe-doped $\mathrm{ZnO}$ with different Fe loadings as catalyst supports for the deposition of Pt NPs. The fabricated Pt-based catalysts were tested using CO oxidation as the probe reaction to study the influence of the metal dopant on catalytic performance. We found that a small amount of Fe dopant enhanced the catalytic activity, which was attributed to an enhancement of the interaction between the Pt NPs and the catalyst support.

\section{Experimental}

\subsection{Preparation of Fe-Doped $\mathrm{ZnO}$ and $\mathrm{Pt} / \mathrm{x} \% \mathrm{FeZnO}$ catalysts}

Fe-doped ZnO samples were synthesized using the coprecipitation method with zinc nitrate as the starting material, ferric nitrate as the doping source, and urea as the precipitator. Aqueous solutions with calculated amounts of metal nitrates (i.e., $\mathrm{Zn}\left(\mathrm{NO}_{3}\right)_{2} \cdot 6 \mathrm{H}_{2} \mathrm{O}$ and $\mathrm{Fe}\left(\mathrm{NO}_{3}\right)_{3} \cdot 9 \mathrm{H}_{2} \mathrm{O}$ ) were prepared separately. They were then mixed and stirred for 2 hours. The urea solution was then slowly added to the above mixture. The final solution was thoroughly stirred for 2 hours, and then heated to and kept at $90{ }^{\circ} \mathrm{C}$ for 1 hour to yield precipitates. The precipitates were collected by centrifugation, washed with distilled water and ethanol, and then dried in an oven at $110{ }^{\circ} \mathrm{C}$ overnight. The dried precipitates were calcined at $600{ }^{\circ} \mathrm{C}$ for 5 hours to obtain Fe-doped $\mathrm{ZnO}$ powders. ZnO was synthesized using the same procedure without adding the Fe precursor. All the samples are denoted as $x \% \mathrm{FeZnO}$, where $x$ (i.e., 0,1 , and 4 ) is the percentage of doped Fe.

Platinum-based catalysts were prepared by the depositionprecipitation method using $\mathrm{H}_{2} \mathrm{PtCl}_{6}$ as the precursor. In a typical preparation, an aqueous solution was prepared containing $600 \mathrm{mg}$ of urea in $40 \mathrm{ml}$ of $\mathrm{H}_{2} \mathrm{O}$, followed by the addition of $900 \mathrm{mg}$ of the $x \% \mathrm{FeZnO}$ sample. The mixture was stirred for 1 hour, and then a solution of $85 \mathrm{mg} \mathrm{H}_{2} \mathrm{PtCl}_{6}$ in $30 \mathrm{ml} \mathrm{H} \mathrm{H}_{2} \mathrm{O}$ was added. The mixture was then stirred for 3 hours and subsequently heated to $90{ }^{\circ} \mathrm{C}$ and aged at that temperature for 2 hours. The mixture was cooled down to room temperature and a solution of $60 \mathrm{mg} \mathrm{NaBH}_{4}$ dissolved in $10 \mathrm{ml} \mathrm{of} \mathrm{H}_{2} \mathrm{O}$ was then added dropwise. The reaction was continued for 1 hour with stirring, and the black precipitate was centrifuged, washed 5 times with water, and dried in an oven overnight at $110{ }^{\circ} \mathrm{C}$. The prepared samples were denoted as $\mathrm{Pt} / x \% \mathrm{FeZnO}$, where $x$ (i.e., 0, 1, and 4) is the percentage of doped Fe.

\subsection{Characterization and catalytic reaction}

The size and morphology of the synthesized catalysts were assessed by transmission electron microscopy (TEM, Tecnai F30 microscopy operated at $300 \mathrm{kV}$ ) accompanied with energy dispersive X-ray spectroscopy (EDS). X-ray diffraction (XRD) patterns of the samples were recorded using a D/MAX-2500 (Rigaku; at $40 \mathrm{kV}$ and $300 \mathrm{~mA}$ ) that scanned $2 \theta$ values between $25^{\circ}$ to $85^{\circ}$. A VG Scientific Sigma Probe X-ray photoelectron spectroscopy (XPS) system equipped with an $\mathrm{Al} \mathrm{K} \alpha$ X-ray source $(1486.3 \mathrm{eV})$ under ultra-high vacuum at $10^{-10}$ Torr was used to analyse the oxidation states of the Pt. Ultraviolet-visible (UV-vis) spectroscopy was carried out on a Lambda 1050 (Perkin Elmer) equipped with $10 \mathrm{~mm}$ quartz cells at room temperature. The Brunauer-Emmett-Teller surface area and pore structure of the synthesized catalysts were determined using the $\mathrm{N}_{2}$ adsorption method (Micromeritics Tristar II 3020 V1.03 Analyzer). The amount of Fe and Pt loading was measured by inductively coupled plasma optical emission spectroscopy (ICP-OES) using a Thermal Scientific iCAP 6300. Metal dispersion on the samples was measured using CO pulse chemisorption (BELCAT-B; BEL Japan Inc.) with a stoichiometry factor of $\mathrm{Pt}: \mathrm{CO}=1: 1$. Pretreatment was done at $250{ }^{\circ} \mathrm{C}$ under $\mathrm{H}_{2}$ flow $(50 \mathrm{sccm})$ for 2 hours. $10 \%$ CO gas balanced with He was used as the gas pulse, and the measurement was carried out at $50{ }^{\circ} \mathrm{C}$.

\subsection{Performance of the CO oxidation reaction}

CO oxidation was carried out in a flow reactor as described elsewhere. ${ }^{25}$ Initially, $50 \mathrm{mg}$ of the catalyst was loaded into a tubular reactor. Before the reaction, the catalyst was reduced at $250{ }^{\circ} \mathrm{C}$ under flowing $\mathrm{H}_{2}\left(5 \% \mathrm{H}_{2}\right.$ in $\left.\mathrm{He}, 45 \mathrm{ml} \mathrm{min}^{-1}\right)$ for 2 hours, and then cooled to room temperature. Product $\mathrm{CO}_{2}$ gas was not detected in the reactor before the reaction started. The reactant gas composition was $4 \% \mathrm{CO}, 10 \% \mathrm{O}_{2}$, and $86 \% \mathrm{He}$ (carrier gas). The total gas flow rate was $50 \mathrm{ml} \mathrm{min}^{-1}$, controlled by mass flow controllers (BROOKS instrument). The space velocity of the reaction was $15000 \mathrm{~h}^{-1}$. CO oxidation was carried out until reaching $100 \%$ CO conversion (at temperatures between 60 and $200{ }^{\circ} \mathrm{C}$ ). The gas mixture passing through the catalyst powder was analysed using gas chromatography (DS science). The turnover frequency (TOF) was calculated based on the active Pt sites measured from the chemisorption of CO. The stability of the catalysts was measured in 5 consecutive heatingcooling cycles. After the first CO oxidation test, the catalysts were cooled down to room temperature for 1 hour under He gas before commencing the next reaction cycle. 


\section{Results and discussion}

\subsection{Characterization of the synthesized Fe-doped ZnO samples}

The crystalline structure of the synthesized $x \% \mathrm{FeZnO}$ samples was investigated using the XRD technique. All the samples exhibited high crystalline hexagonal wurtzite belonging to the $\mathrm{C}_{6}^{4}$ space groups $\left(\mathrm{PG}_{3} \mathrm{mc}\right)$ of $\mathrm{ZnO}$ (JPCDS card no. 36-1451) without detecting other crystalline phases or impurities (Fig. 1a). The ionic replacement of the dopant into the lattice of the host material results in a slight distortion of the unit cell, which leads to a small shift of all the strong diffraction peaks in the XRD patterns. From the magnified (101) diffraction peaks for all the samples (Fig. 1b), the peak for the $1 \%$ FeZnO sample did not show a considerable shift compared with that for $\mathrm{ZnO}$, which was probably caused by the very small Fe dopant loading. However, the peak shift towards the lower $2 \theta$ angle for the $4 \% \mathrm{FeZnO}$ sample compared with the other two was easily distinguished. The shift can be attributed to the compressive stress of the unit cell in the crystal structure when ions with larger radii were used as the dopant. Because the ionic radii of iron and zinc are different $\left(\mathrm{Fe}^{2+}: 0.074 \mathrm{~nm}, \mathrm{Fe}^{3+}\right.$ : $0.064 \mathrm{~nm}$, and $\left.\mathrm{Zn}^{2+}: 0.072 \mathrm{~nm}\right),{ }^{26}$ it is likely that $\mathrm{Fe}^{2+}$ ions were substituted into the $\mathrm{Zn}$ site. A similar observation has been interpreted from the incorporation of Fe dopant ions into the lattice of ZnO host structures. ${ }^{27-29}$ The data obtained from XRD indicated that the Fe dopant did not form crystalline segregated bi-phases, but was well-incorporated into the $\mathrm{ZnO}$ crystal lattice. Higher Fe loading can result in the formation of $\mathrm{ZnFe}_{2} \mathrm{O}_{4}$ and $\mathrm{Fe}_{2} \mathrm{O}_{3}$ phases. ${ }^{30}$ Because the focus of this work is to study the influence of metal doping on catalytic activity for $\mathrm{CO}$ oxidation, other crystalline structures than Fe-doped $\mathrm{ZnO}$ should not exist. Hence, we limited the Fe loading to $4 \%$ to prevent the emergence of new crystalline phases in the samples.

The optical band gap of the materials was estimated using UV-vis spectroscopy based on the absorption peak centered at around $370 \mathrm{~nm}$ in each sample, as seen in Fig. 2a. The data in Fig. 2b, which shows Tauc's plot for band gap estimation, exhibited a downward trend as the amount of Fe doping increased (see Table 1). This is consistent with the gradual change in colour from the light white of $\mathrm{ZnO}$ to the orange of $4 \%$ FeZnO (ESI Fig. S1 $\dagger$ ) and is explained by the formation of defect states in the band gap by the transfer of $3 \mathrm{~d}$ electrons from
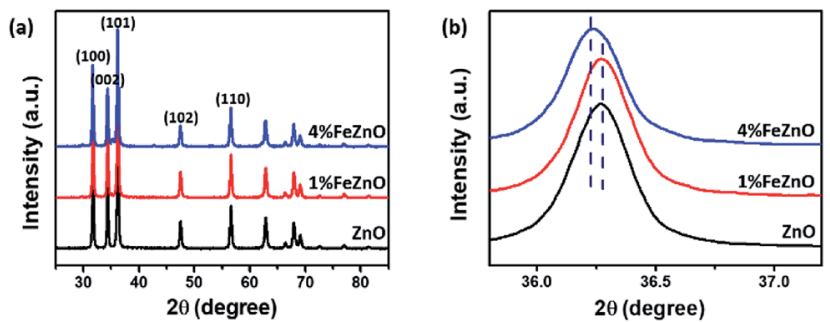

Fig. 1 (a) XRD patterns of the synthesized $x \% F e Z n O$ samples. (b) The (101) diffraction peaks that show a shift between the samples.
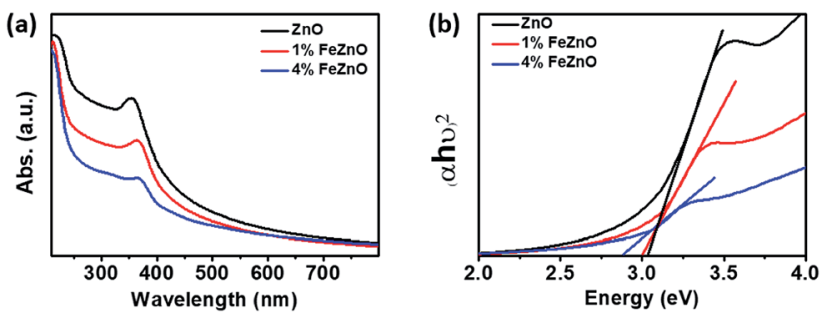

Fig. 2 (a) UV-vis absorption spectra and (b) Tauc's plot for optical band gap estimation of the $x \% \mathrm{FeZnO}$ samples.

the trivalent dopants (e.g., $\mathrm{Fe}^{3+}, \mathrm{Al}^{3+}, \mathrm{Ga}^{3+}$ ) to the conduction band of the n-type semiconductors. ${ }^{21,31}$ The UV-vis data provide further evidence supporting the successful doping of Fe into the ZnO.

The texture properties of the $x \% \mathrm{FeZnO}$ samples were assessed using $\mathrm{N}_{2}$ adsorption-desorption analysis (see Table 1). The ZnO sample exhibited the lowest surface area, whereas loading small amounts of $\mathrm{Fe}$ (i.e., 1 and $4 \%$ ) showed a negligible difference in both the surface area and average pore size compared with the ZnO sample. The surface areas of all the samples were relatively small, with the highest at $14.3 \mathrm{~m}^{2} \mathrm{~g}^{-1}$ for the $4 \% \mathrm{FeZnO}$ sample. Table 1 also provides the actual $\mathrm{Fe}$ loading of the synthesized $x \% \mathrm{FeZnO}$, as determined using ICPOES analysis. The actual Fe loadings were about $1 \%$ and $4 \%$, which are in good agreement with the calculated values.

\subsection{Characterization of the synthesized Pt $/ x \% F e Z n O$ catalysts}

The real amount of Pt loading (see Table 2) was measured using ICP-OES analysis. In general, the Pt loading was similar in all the samples, implying the insignificant role of this factor when comparing the catalytic activity. XPS analysis was performed to investigate the surface oxidation states of the Pt NPs in each sample. All the Pt peaks were calibrated based on adjusting the C $1 \mathrm{~s}$ peak position to $284.8 \mathrm{eV}$. Fig. 3a-c shows the XPS spectra after fitting using the CasaXPS program. In all the samples, the Pt $4 \mathrm{f}$ peaks were composed of both the metallic $\left(\mathrm{Pt}^{0}\right)$ and oxidation $\left(\mathrm{Pt}^{2+}\right.$ and $\left.\mathrm{Pt}^{4+}\right)$ states; ${ }^{32}$ however, the former was predominant, which was most likely because of the use of the strong reductant $\mathrm{NaBH}_{4}$ in the preparation step. It is worth noting that all the $\mathrm{Pt}$ if peaks for the $\mathrm{Pt} / 4 \% \mathrm{FeZnO}$ sample shifted to a lower binding energy (i.e., $\sim 0.2 \mathrm{eV}$ ) in comparison with those for the $\mathrm{Pt} / \mathrm{ZnO}$ catalyst, indicating that the surface of the Pt NPs in the Pt $/ 4 \% \mathrm{FeZnO}$ catalyst had a higher electron density because of electron transfer from the support. Moreover, Fig. 3d exhibited a downward trend for the oxide fraction of the Pt with the increase in Fe dopant loading, namely from $44.4 \%$ in the $\mathrm{Pt} / \mathrm{ZnO}$ catalyst to $34.7 \%$ in the $\mathrm{Pt} / 4 \% \mathrm{FeZnO}$ catalyst, which is consistent with the conclusion inferred from the observed peak shift. Data obtained from the XPS analysis suggest that $4 \% \mathrm{FeZnO}$ has the strongest interaction with the Pt NPs. The electronic states of the Fe and $\mathrm{Zn}$ were also analysed to provide more details about the charge transfer phenomenon. XPS spectra of the Fe 2p and Zn 2p core levels for all the samples 
Table 1 Actual iron loadings, physicochemical properties, and band gap estimates of the synthesized $x \% \mathrm{FeZnO}$

\begin{tabular}{|c|c|c|c|c|}
\hline Sample notation & Fe loading (wt\%) & Surface area $\left(\mathrm{m}^{2} \mathrm{~g}^{-1}\right)$ & Average pore size (nm) & Band gap estimate \\
\hline $\mathrm{ZnO}$ & 0.00 & 11.90 & 16.40 & 3.04 \\
\hline $1 \% \mathrm{FeZnO}$ & 1.09 & 13.00 & 18.90 & 3.00 \\
\hline
\end{tabular}

Table 2 Characterization and catalytic activity of the synthesized Pt/x\%FeZnO catalysts

\begin{tabular}{|c|c|c|c|c|c|c|c|}
\hline Samples & $\begin{array}{l}\text { Pt wt\% } \\
\text { (ICP-OES) }\end{array}$ & $D_{\mathrm{Pt}}(\mathrm{nm})$ & \multicolumn{2}{|l|}{ Pt dispersion (\%) } & $T_{100}\left({ }^{\circ} \mathrm{C}\right)$ & $\begin{array}{l}\text { TOF }\left(\mathrm{s}^{-1}\right) \\
\text { at } 126^{\circ} \mathrm{C}\end{array}$ & $E_{\mathrm{a}}\left(\mathrm{kcal} \mathrm{mol}{ }^{-1}\right)$ \\
\hline $\mathrm{Pt} / 1 \% \mathrm{FeZnO}$ & 2.08 & 2.50 & 3.21 & 1.86 & 138 & 1.34 & 11.80 \\
\hline $\mathrm{Pt} / 4 \% \mathrm{FeZnO}$ & 2.04 & 2.40 & 3.48 & 3.01 & 126 & 5.37 & 8.66 \\
\hline
\end{tabular}

were collected and shown in ESI Fig. S3. $\uparrow$ The Fe 2p peaks in ESI Fig. S3a $\uparrow$ showed very low intensity because of the small amount of Fe existing on the surface of the FeZnO support. It should be noted that only small Fe loadings, namely, $1 \%$ and $4 \%$ were introduced to the ZnO. Moreover, because Fe was well-doped into $\mathrm{ZnO}$ lattice, a major fraction of the Fe is located deep inside the bulk. XPS analysis, which can only detect the elemental composition of the surface of substances (about several atomic layers), therefore, showed very low-intensity $\mathrm{Fe}$ $2 \mathrm{p}$ peaks. On the other hand, the $\mathrm{Zn} 2 \mathrm{p}$ core level of all the samples, as seen in ESI Fig. S3b, $\uparrow$ did not show any peak shift, which was most likely because the $\mathrm{Zn} 2 \mathrm{p}$ spectra reflected the electronic status of the $\mathrm{Zn}^{2+}$ ions in the $\mathrm{ZnO}$ lattice, which were predominant in comparison with those existing at the interface between the FeZnO support and the Pt NPs.

Fig. 4 shows TEM images of the synthesized $\mathrm{Pt} / x \% \mathrm{FeZnO}$ catalysts and their corresponding particle size distributions. The Pt NPs can be observed as small dark spots, while the catalyst supports are brighter. The inset HR-TEM images show a random Pt NP on each sample. The lattice fringe was $0.225 \mathrm{~nm}$ in all cases, which is attributed to the Pt (111) surface (JCPDS card no. 65-2868). To get additional evidence of the Pt
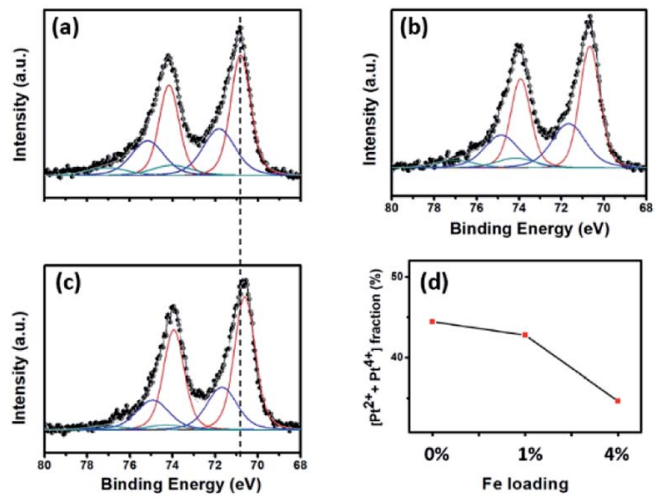

Fig. 3 XPS analysis of the Pt $4 f$ core level for the (a) Pt/ZnO, (b) Pt/1\% $\mathrm{FeZnO}$, (c) Pt/4\%FeZnO catalysts; the dashed line shows the peak shift between the $\mathrm{Pt} / \mathrm{ZnO}$ and $\mathrm{Pt} / 4 \% \mathrm{FeZnO}$ samples. (d) A comparison of the oxide fraction of $\mathrm{Pt}$ in the catalysts as a function of Fe loading. deposition, EDS mapping of a random area on the Pt/4\%FeZnO sample, which is representative of the whole, was carried out. As seen in ESI Fig. S2, $\uparrow$ the EDS mapping data clearly confirm the existence of Pt. Both the TEM and EDS data ascertained the successful deposition of Pt NPs on the synthesized $x \% \mathrm{FeZnO}$ supports. From the EDS mapping, it is worth noting that a homogeneous distribution of $\mathrm{Zn}$ and $\mathrm{Fe}$ could also be observed across the entire mapped area, which further supported the successful doping of Fe into the ZnO. A statistic survey of 200 particles was performed to evaluate the size distribution of the Pt NPs in each sample. The average Pt NP diameters $\left(D_{\mathrm{Pt}}\right)$ were $2.2,2.5$, and $2.4 \mathrm{~nm}$ for 0,1 , and $4 \% \mathrm{Fe}$ loading, respectively (see Table 2). Although the mean sizes of the Pt NPs in all the catalysts were similar, we can see from the TEM images that the metal NPs were well dispersed on the $4 \%$ FeZnO support; while on the ZnO, the NPs migrated close to one another to form local domains with high NP density. The difference in dispersion behaviour for the Pt NPs could be explained by the strength of the interaction between the Pt NPs and the supports. When preparing catalysts using the deposition-precipitation method, the hydroxide form of the Pt was initially anchored on the surface of the support. During the reduction process to induce the Pt NPs, there is a tendency for the Pt NPs to agglomerate to minimize surface energy. When the interaction between the Pt NPs and surface of the support
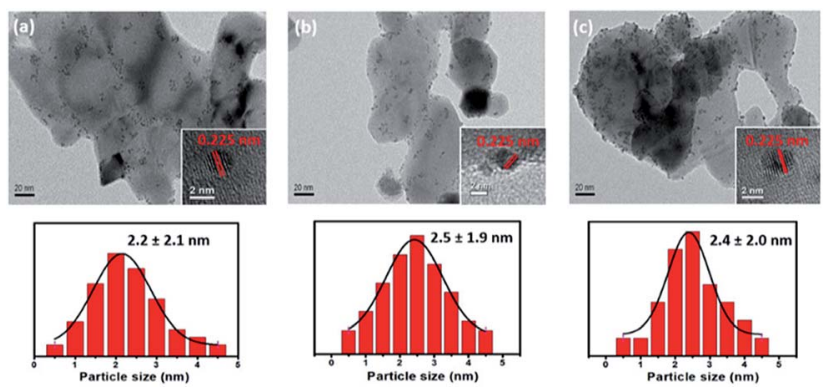

Fig. 4 TEM images of the synthesized (a) Pt/ZnO, (b) Pt/1\%FeZnO, (c) $\mathrm{Pt} / 4 \% \mathrm{FeZnO}$ catalysts and their corresponding particle size distributions. 
was strong enough to overcome the agglomeration force, the Pt NPs could grow well dispersed across the surface. With a somewhat weaker interaction between the Pt NPs and the surface of the support, agglomeration of the Pt NPs could occur during NP growth, but quite slowly. Due to the relatively low rate of agglomeration in comparison with that of reduction, the $\mathrm{Pt}$ NPs would still have similar sizes as in the abovementioned case, but they assembled closer to each other to form local domains with high NP density, as seen in the Pt/ZnO catalyst. Otherwise, if this interaction was very weak or depleted, the Pt NPs would aggregate to become larger NPs. From the dispersion behaviour of the Pt NPs on each support, we assume that there is a stronger interaction between the Pt NPs and the $4 \% \mathrm{Fe}$ loading sample compared with the other samples. To confirm this assumption, Pt dispersion for all the synthesized catalysts before and after the CO oxidation reaction was evaluated using the CO chemisorption method (see Table 2). While Pt dispersion on the $\mathrm{Pt} / 4 \% \mathrm{FeZnO}$ sample decreased slightly after the reaction from 3.48 to $3.01 \%$, Pt dispersion on the other samples dropped significantly. This agrees well with the TEM images of the catalysts after CO oxidation (ESI Fig. S4 $\dagger$ ), which exhibited sintering of the Pt NPs to form larger NPs in the Pt/ZnO and Pt/ $1 \%$ FeZnO samples. Combined with the XPS data, the TEM observations and the chemisorption data clearly indicate that $\mathrm{Pt}$ NPs have the strongest interaction with the $4 \% \mathrm{FeZnO}$ support, thus resulting in the best NP sintering resistance.

\subsection{CO oxidation of the synthesized $\mathrm{Pt} / x \% \mathrm{FeZnO}$ catalysts}

The dependence of CO conversion on the reaction temperature for all the synthesized catalysts is depicted in Fig. 5a. Generally, CO conversion increases with higher reaction temperatures. The temperatures corresponding to $100 \%$ CO conversion $\left(T_{100}\right)$ decreased with higher Fe dopant loading. These temperatures were 147,138 , and $126{ }^{\circ} \mathrm{C}$ with for 0,1 , and $4 \%$ Fe loading, respectively (see Table 2 ). The TOF of the synthesized catalysts, based on the Pt chemisorption analysis and calculated at $126{ }^{\circ} \mathrm{C}$, increased significantly with higher Fe dopant loading, namely $0.60,1.34$, and $5.37 \mathrm{~s}^{-1}$ for 0,1 , and $4 \%$ Fe loading, respectively. The activation energies $\left(E_{\mathrm{a}}\right)$ of the CO oxidation reaction for the synthesized Pt-based catalysts were calculated from the Arrhenius plot (Fig. 5b). The 4\% Fe loading catalyst had the smallest $E_{\mathrm{a}}$ value of $8.66 \mathrm{kcal} \mathrm{mol}^{-1}$, while the $E_{\mathrm{a}}$ values for the $\mathrm{Pt} / \mathrm{ZnO}$ and $\mathrm{Pt} / 1 \% \mathrm{FeZnO}$ catalyst were 13.0 and $11.8 \mathrm{kcal} \mathrm{mol}^{-1}$, respectively. From the abovementioned results, it was concluded that the catalytic activity for the CO oxidation reaction increases with increased Fe loading. Because long-term
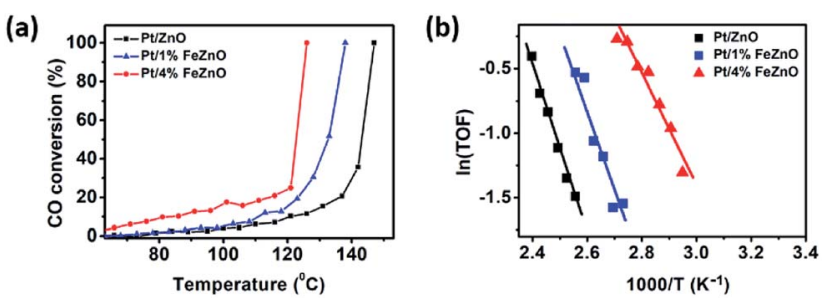

Fig. 5 (a) $\mathrm{CO}$ conversion as a function of temperature and (b) Arrhenius plot for the synthesized $\mathrm{Pt} / \mathrm{x} \% \mathrm{FeZnO}$ catalysts.

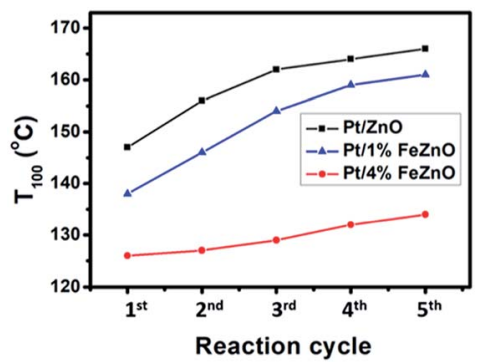

Fig. 6 Stability test for the synthesized Pt/x\%FeZnO catalysts during the $\mathrm{CO}$ oxidation reaction.

durability is among the most vital factors for evaluating catalysts, we also investigated the stability of the synthesized catalysts by performing the reaction for five consecutive heatingcooling cycles. The Pt/4\%FeZnO catalyst, which had the advantage of higher catalytic activity, also exhibited better stability compared with the others. The $T_{100}$ for this sample only increased slightly, whereas the $T_{100}$ for the other two catalysts rose dramatically during the five consecutive cycles (Fig. 6).

The electronic and geometric effects are plausible explanations for the improved catalytic activity and stability. In our study, the enhanced activity and stability of the Pt $/ x \% \mathrm{FeZnO}$ catalysts could be attributed to the presence of the Fe dopant (as confirmed by XRD results), which improved electron transfer between the Pt NPs and the support. Enhancement of electron transfer between the metal and the support indicates a stronger metal-support interaction, which could stabilize the NPs and prevent them from sintering. ${ }^{22}$ As a result, the $\mathrm{Pt} / 4 \% \mathrm{FeZnO}$ catalyst, which had the strongest interaction between the Pt NPs and the support, exhibited the highest sintering resistance, as is evident from the TEM image (ESI Fig. S4†) and the chemisorption data after the reaction, which thus promotes both the catalytic activity and stability. Metal particle sintering has been an intrinsic problem for improving catalyst performance and stability. ${ }^{33,34}$ Particularly, the detrimental effect of Pt sintering on the catalytic $\mathrm{CO}$ oxidation reaction has been reported elsewhere. For instance, in comparison with a $\mathrm{Pt} / \mathrm{SiO}_{2}$ catalyst calcined at $600{ }^{\circ} \mathrm{C}$, Jung et al. observed a decrease in catalytic activity for the $\mathrm{CO}$ oxidation reaction when the catalyst was calcined at $750{ }^{\circ} \mathrm{C}^{25}$ Accordingly, the sintering effect that deactivated the Pt NPs was the main reason for the drop in catalytic performance. Yang et al. systematically investigated the link between sintering in a $\mathrm{Pt} / \mathrm{Al}_{2} \mathrm{O}_{3}$ catalyst and its activity for $\mathrm{CO}$ oxidation. ${ }^{35}$ They found an apparent relation between the degree of metal sintering and the loss of catalytic activity. In the current work, sintering to form larger Pt NPs is assumed to occur at high temperature under the oxidative conditions over the course of the reaction resulting from a weak metal-support interaction. A study of Pt size evolution using an in situ TEM technique with the $\mathrm{CO}$ oxidation reaction over a $\mathrm{Pt} / \mathrm{ZnO}$ catalyst would be able to provide a direct observation of this sintering process. Nevertheless, the work reported here may provide inspiration for the use of a metal dopant as an efficient approach for designing metal-oxide support catalysts to achieve better catalytic performance. 


\section{Conclusions}

A series of Fe-doped $\mathrm{ZnO}$ materials with different Fe loading (i.e., 0, 1, and $4 \%$ ) were synthesized via the co-precipitation method followed by calcination. Pt NPs were deposited on the $x \% \mathrm{FeZnO}$ samples using deposition-precipitation to fabricate catalysts for the $\mathrm{CO}$ oxidation reaction. Characterization of all the samples using TEM, XRD, EDS, and UV-vis indicated that the Fe ions were well-doped into the $\mathrm{ZnO}$ lattice and that the $\mathrm{Pt}$ NPs were successfully grown on the supports. For the CO oxidation reaction, we found that the catalytic activity of the synthesized catalysts was enhanced with increased Fe loading, with the highest TOF value of $5.37 \mathrm{~s}^{-1}$ at $126{ }^{\circ} \mathrm{C}$ from the $\mathrm{Pt} / 4 \%$ FeZnO catalyst. The increased Fe doping promoted the interaction between the Pt NPs and the support, leading to a higher resistance for metal sintering, which resulted in the increase in catalytic activity.

\section{Conflicts of interest}

There are no conflicts to declare.

\section{Acknowledgements}

This work was supported by the Institute for Basic Science (IBS) [IBS-R004].

\section{Notes and references}

1 G. M. Schwab and K. Koller, J. Am. Chem. Soc., 1968, 90, 3078-3080.

2 S. J. Tauster, S. C. Fung and R. L. Garten, J. Am. Chem. Soc., 1978, 100, 170-175.

3 S. M. Kim, H. Lee and J. Y. Park, Catal. Lett., 2015, 145, 299308.

4 K. V. Kovtunov, D. A. Barskiy, O. G. Salnikov, D. B. Burueva, A. K. Khudorozhkov, A. V. Bukhtiyarov, I. P. Prosvirin, E. Y. Gerasimov, V. I. Bukhtiyarov and I. V. Koptyug, ChemCatChem, 2015, 7, 2581-2584.

5 X. Liu, M. H. Liu, Y. C. Luo, C. Y. Mou, S. D. Lin, H. Cheng, J. M. Chen, J. F. Lee and T. S. Lin, J. Am. Chem. Soc., 2012, 134, 10251-10258.

6 J. Y. Park, L. R. Baker and G. A. Somorjai, Chem. Rev., 2015, 115, 2781-2817.

7 W. Wang, X. Li, Y. Zhang, R. Zhang, H. Ge, J. Bi and M. Tang, Catal. Sci. Technol., 2017, 7, 4413-4421.

$8 \mathrm{M} . \mathrm{Xu}, \mathrm{S}$. He, H. Chen, G. Cui, L. Zheng, B. Wang and M. Wei, ACS Catal., 2017, 7, 7600-7609.

9 Q. Fu and T. Wagner, Surf. Sci. Rep., 2007, 62, 431-498.

10 N. Kamiuchi, T. Matsui, R. Kikuchi and K. Eguchi, J. Phys. Chem. C, 2007, 111, 16470-16476.

11 S. M. Kim, S. W. Lee, S. Y. Moon and J. Y. Park, J. Phys.: Condens. Matter, 2016, 28, 254002.
12 D. Park, S. M. Kim, S. H. Kim, J. Y. Yun and J. Y. Park, Appl. Catal., A, 2014, 480, 25-33.

13 M. A. Bañares, Catal. Today, 1999, 51, 319-348.

14 D. W. Lee and B. R. Yoo, J. Ind. Eng. Chem., 2014, 20, 39473959.

15 Z. Zhang, J. Liu, J. Gu, L. Su and L. Cheng, Energy Environ. Sci., 2014, 7, 2535-2558.

16 W. Cen, Y. Liu, Z. Wu, H. Wang and X. Weng, Phys. Chem. Chem. Phys., 2012, 14, 5769-5777.

17 D. M. Jang, I. H. Kwak, E. L. Kwon, C. S. Jung, H. S. Im, K. Park and J. Park, J. Phys. Chem. C, 2015, 119, 1921-1927.

18 M. H. Park, J. H. Li, A. Kumar, G. Li and Y. Yang, Adv. Funct. Mater., 2009, 19, 1241-1246.

19 L. R. Baker, A. Hervier, H. Seo, G. Kennedy, K. Komvopoulos and G. A. Somorjai, J. Phys. Chem. C, 2011, 115, 16006-16011.

20 K. C. Goddeti, S. M. Kim, Y. K. Lee, S. H. Kim and J. Y. Park, Catal. Lett., 2014, 144, 1411-1417.

21 J. Schumann, M. Eichelbaum, T. Lunkenbein, N. Thomas, M. C. Álvarez Galván, R. Schlögl and M. Behrens, ACS Catal., 2015, 5, 3260-3270.

22 S. Y. Peng, Z. N. Xu, Q. S. Chen, Z. Q. Wang, D. M. Lv, J. Sun, Y. Chen and G. C. Guo, ACS Catal., 2015, 5, 4410-4417.

23 Ü. Özgür, Y. I. Alivov, C. Liu, A. Teke, M. A. Reshchikov, S. Doğan, V. Avrutin, S. J. Cho and H. Morkoç, J. Appl. Phys., 2005, 98, 041301.

24 S. J. Young, C. C. Yang and L. T. Lai, J. Electrochem. Soc., 2017, 164, B3013-B3028.

25 C. H. Jung, J. Yun, K. Qadir, B. Naik, J. Y. Yun and J. Y. Park, Appl. Catal., B, 2014, 154-155, 171-176.

26 R. D. Shannon, Acta Crystallogr., Sect. A: Cryst. Phys., Diffr., Theor. Gen. Crystallogr., 1976, 32, 751-767.

27 S. Kumar, K. Asokan, R. K. Singh, S. Chatterjee, D. Kanjilal and A. K. Ghosh, J. Appl. Phys., 2013, 114, 164321.

28 C. Wang, Z. Chen, Y. He, L. Li and D. Zhang, Appl. Surf. Sci., 2009, 255, 6881-6887.

29 X. Wu, Z. Wei, L. Zhang, X. Wang, H. Yang and J. Jiang, J. Nanomater., 2014, 2014, 6.

30 J. J. Beltran, C. A. Barrero and A. Punnoose, Phys. Chem. Chem. Phys., 2015, 17, 15284-15296.

31 A. Kumbhar and G. Chumanov, J. Nanopart. Res., 2005, 7, 489-498.

32 S. Y. Moon, B. Naik, C. H. Jung, K. Qadir and J. Y. Park, Catal. Today, 2016, 265, 245-253.

33 P. Munnik, M. E. Z. Velthoen, P. E. de Jongh, K. P. de Jong and C. J. Gommes, Angew. Chem., Int. Ed., 2014, 53, 94939497.

34 G. Prieto, J. Zečević, H. Friedrich, K. P. de Jong and P. E. de Jongh, Nat. Mater., 2012, $12,34$.

35 J. Yang, V. Tschamber, D. Habermacher, F. Garin and P. Gilot, Appl. Catal., B, 2008, 83, 229-239. 